\title{
Further evidence for differential regulation of follicle- stimulating hormone (FSH) and luteinizing hormone (LH): increased FSH and decreased LH levels in a patient with familial pure gonadal dysgenesis
}

\author{
V. Popovic, D. Micic, S. Damjanovic, Lj. Calovic ${ }^{1}$, Z. Rolovic ${ }^{2}$, A. Mijovic ${ }^{2}$, \\ M. Petakov, D. Manojlovic and J. Micic
}

\begin{abstract}
Institute of Endocrinology, University Clinical Center, School of Medicine, Belgrade, ${ }^{1}$ Department of Internal Medicine, Titograd, and ${ }^{2}$ Institute of Haematology, University Clinical Center, Belgrade, Yugoslavia
\end{abstract}

\begin{abstract}
Summary: There is experimental evidence that a portion of follicle-stimulating hormone (FSH) secretion is independent of hypothalamic influences. A 29 year old woman with familial pure gonadal dysgenesis developed myelodysplastic syndrome. Endocrine investigations showed discrepancy between serum FSH and luteinizing hormone (LH) levels. FSH levels remained elevated while LH levels decreased. The FSH to LH ratio was 10 (normal 2-2.5). The fall in $\mathrm{LH}$ is likely to be due to factor(s) involved directly and specifically in LH synthesis and release. Exogenous LH releasing hormone administration as well as hormonal replacement treatment increased LH levels. The FSH to LH ratio decreased to 7. This case supports the hypothesis of differential regulation of FSH and LH, and that FSH secretion is at least partly autonomous.
\end{abstract}

\section{Introduction}

The data presented in the study of DePaolo ${ }^{1}$ clearly demonstrate that increased release of follicle stimulating hormone (FSH) after ovariectomy can occur from pituitary allografts isolated from the hypothalamus for several weeks, suggesting a hypothalamus-independent autonomous component of FSH secretion. Whether this autonomous secretion is a passive process, or driven by stimulatory pituitary paracrine factors or is modulated by ovarian activin are the questions to be answered. These findings in experimental conditions prompted us to report a patient with familial pure gonadal dysgenesis ${ }^{2}$, partially empty sella and myelodysplastic syndrome, who provides an in vivo model supporting the differential regulation of FSH and luteinizing hormone (LH).

Correspondence: Professor Dr Vera Popovic, Institute of Endocrinology, University Clinical Center, Ul.dr. Subotic 13, 11000 Belgrade, Yugoslavia.

Accepted: 21 April 1992

\section{Case report}

A 29 year old female presented in 1989 with amenorrhoea, failure of sexual maturation, and severe anaemia. In 1982 she had undergone investigations for primary amenorrhoea and failure of sexual maturation, and was found to have high serum FSH (range 76-80 IU/1) and LH (range 37-58 IU/l) in association with the low oestradiol levels $(90 \mathrm{pmol} / \mathrm{l})$ and normal karyotype $46 \mathrm{XX}$. The FSH to LH ratio was 2 . Laparoscopy showed a small hypoplastic uterus, normal-looking Fallopian tubes and that both ovaries were small, with a thin white capsule. Ovarian biopsy could not demonstrate the presence of primordial follicles. Pure gonadal dysgenesis was diagnosed and cyclical replacement therapy with oestrogen and progesterone was prescribed.

She did not take hormone replacement treatment regularly and had not taken any treatment for a year prior to this admission. Family history revealed that her two sisters (aged 42 and 37 years) also had primary amenorrhoea and failure of sexual maturation. Pure gonadal dygenesis was 
diagnosed in both sisters by the $46 \mathrm{XX}$ karyotype and elevated gonadotrophin levels. Body mass index was normal $\left(24 \mathrm{~kg} / \mathrm{m}^{2}\right)$. Sexual maturation for breasts and pubic hair was Tanner stage 2 . Peripheral blood showed anaemia, neutropenia and thrombocytopenia while the bone marrow aspirate was dysplastic. A diagnosis of refractory anaemia with excess of blasts was established.

\section{Results}

Baseline concentrations of gonadotrophins and sex steroids

Blood samples were taken six times at random and FSH concentrations were markedly raised (range $25 \pm 3-33 \pm 5 \mathrm{IU} / \mathrm{l})$ in comparison with those of normal adult females (FSH: 3-11 IU/1, RIA Serono). Basal $\mathrm{LH}$ concentrations were $2 \pm 1-3 \pm 9$ IU/1 within the normal range for adult females (LH; 0.5-11 IU/1, RIA Serono). The ratio of FSH to $\mathrm{LH}(10)$ was markedly raised. The concentration of oestradiol (range 43-55 pmol/1, RIA Serono) was well below the normal adult female range (110-1,211 pmol/1, RIA Serono), whilst androstenedione $(5.0 \mathrm{nmol} / \mathrm{l})$, testosterone $(2.7 \mathrm{nmol} / \mathrm{l})$ and dehydroepiandrosterone (DHEAS) $(3.2 \mathrm{nmol} /$ 1) were within the range for normal females.

\section{Stimulation tests}

Human chorionic gonadotrophin (2,000 IU) i.m. on days 0 and 3 failed to stimulate any increase in 48 hours in the plasma concentrations of oestradiol ( 55 to $50 \mathrm{pmol} / \mathrm{l})$ or testosterone $(2.7$ to $2.1 \mathrm{nmol} / \mathrm{l})$. Administration of menotrophin (Pergonal) (225 IU) on each of four successive days did not cause any change in the plasma concentrations of oestradiol (55 to $45 \mathrm{pmol} / \mathrm{l})$. After $100 \mu \mathrm{g} \mathrm{LH}$ releasing hormone (LHRH) i.v., LH concentrations rose from $2.0 \mathrm{IU} / 1$ at 0 minutes to $6.0 \mathrm{IU} / 1$ at 20 minutes.

Exogenous pulsatile i.v. LHRH, delivered in the dose of $5.6 \mu \mathrm{g} / 90$ minutes/day i.v., by a Graseby 27 minipump, was administered for a period of 7 days. Blood samples for gonadotrophins were taken every 10 minutes on days $0,1,3,5$ and 7 between two pulses of LHRH delivery ( 90 minutes). Table I shows the responses. Concentrations of oestradiol after 7 days of pulsatile LHRH stimulation remained low $(55 \mathrm{pmol} / \mathrm{l})$.

\section{Hormone replacement therapy}

Ethinyl oestradiol and progestogen administration (combined oral contraceptive, Cycloprogynova) for a period of 2 months was followed by a rise in LH (3.0 to $13.6 \mathrm{IU} / \mathrm{l})$ and decline in FSH (30.1 to $19.6 \mathrm{IU} / 1)$.
Table I Plasma gonadotrophin levels [mean ( \pm SE)] after LHRH stimulation

\begin{tabular}{|c|c|c|c|}
\hline Day & $L H(I U / l)$ & $F S H(I U / l)$ & $F S H / L H$ \\
\hline 0 & $3.0(0.3)$ & $30.1(1.3)$ & 10 \\
\hline 1 & $4.6(0.1)$ & $46.5(0.2)$ & 10 \\
\hline 3 & $7.4(0.1)$ & $53.9(0.3)$ & 7 \\
\hline 5 & $7.1(0.2)$ & $54.5(0.7)$ & 7 \\
\hline 7 & $6.5(0.1)$ & $54.2(0.4)$ & 8 \\
\hline
\end{tabular}

Normal pituitary endocrine function (for growth hormone, prolactin, thyroid stimulating hormone $\vec{\circ}$ and $\mathrm{ACTH}$ ) was found during insulin tolerance 3 . and thyrotrophin releasing hormone tests. An ${ }_{\infty}$ $\mathrm{X}$-ray of the pituitary fossa was normal. Magnetic $\circ$ resonance of the pituitary and hypothalamic region $O$ identified a partially empty fossa. There was no 0 pressure on the pituitary stalk.

\section{Discussion}

We have presented a patient with considerable elevation of the FSH to LH ratio which was found $\mathbb{D}$ after she developed dysplastic refractory anaemiag In normal hypergonadotrophic hypogonadal states such as menopause and other causes of primas ovarian failure, such as pure gonadal dygenesis, the FSH to LH ratio is usually $2-2.5$ and this was the case in our patient 8 years previously. We postulate that the factor(s) responsible directly and specifically for LH synthesis and release are involved.

One possibility is the functional failure of appro- $\overrightarrow{\overrightarrow{0}}$ priate hypothalamic LHRH secretion related to 3 chronic disease in the myelodysplastic syndrome. LH is a neuroendocrine marker of gonadotroph stimulation by LHRH. It has been previously $\frac{}{0}$ reported that a log linear relationship exists between the bolus dose of LHRH and the amplitude of ensuing LH pulse in LHRH-deficient individuals. ${ }^{4}$ The magnitude of $\mathrm{LH}$ response to LHRH is thus dose dependent. During the 7 day stimulation of LH secretion in our patient, the LH 을 pulse amplitudes doubled but did not achieve the $D$ levels before the LHRH-deficient state, since we used only one dose and the oestradiol level was low. When our patient received ethyl oestradiol and progestogen replacement treatment, LH concen- $N$ trations rose as expected, since oestradiol enhances $\stackrel{N}{\omega}$ the pituitary responses to successive identical $\underset{\sigma}{0}$ LHRH stimuli and increases the secretory rate for $c$ LH. ${ }^{5}$

Pulsatile FSH secretion or a correlation between $\stackrel{\mathcal{D}}{+}$ FSH secretion and LHRH has been difficult to 0 document. ${ }^{6}$ It is becoming increasingly evident that a portion of FSH secretion is independent of 
hypothalamic influences and that there is an autonomous component of FSH secretion. Median eminence lesions made in ovariectomized rats dramatically stopped LH hypersecretion but only partially reduced plasma FSH levels. ${ }^{7}$

Another possibility could be iron overload due to dysplastic refractory anaemia or transfusion therapy, but one would expect that both gonadotrophins would be decreased, and that the pituitary would not respond to exogenous LHRH stimulation. Prior to admission our patient received only two blood transfusions, and there was no blood biochemical evidence of iron overload.

Isolated LH deficiency due to 'empty fossa' is dismissed as not being pertinent to the argument as all other anterior pituitary hormones were unaffected.

\section{References}

1. DePaolo, L. Hypersecretion of follicle-stimulating hormone (FSH) after ovariectomy of hypophysectomized, pituitarygrafted rats: implications for local regulatory control of FSH. Endocrinology 1991, 128: 1731-1740.

2. Nazareth, H.R., Farah, L., Cuniha, A. et al. Pure gonadal dysgenesis (type XX). Report on a family with four affected sibs. Hum Genet 1977, 37: 117-120.

3. Bennet, J.M., Catovsky, D., Daniel, M., Flandrin, G., Galton, D., Gralnick, H. \& Sultan, C. Proposals for the classification of the myelodysplastic syndromes. $\mathrm{Br} \mathrm{J} \mathrm{Haem-}$ atol 1982, 51: 189-199.

4. Spratt, D.I., Finkelstein, J.S., Badger, T.M., Butler, J.P. \& Crowly, W.F. Bio- and immunoreactive luteinizing hormone responses to low doses of gonadotropin-releasing hormone (GnRH): dose response curves in GnRH-deficient men. $J$ Clin Endocrinol Metab 1986, 63: 143-150.

5. Urban, R., Veldhius, J. \& Dufau, M. Estrogen regulates the gonadotrophin-releasing hormone-stimulated secretion of biologically active luteinizing hormone. J Clin Endocrinol Metab 1991, 72: 660-668.

6. Levine, E. \& Duffy, M. Simultaneous measurement of luteinizing hormone (LH)-releasing hormone, LH, and follicle-stimulating hormone release in intact and short term castrate rats. Endocrinology 1988, 122: 2211-2221.
Different in vivo models have been used for studying regulation of FSH secretion. DePaolo' showed that increased release of FSH after acute ovariectomy can occur from pituitary allographs isolated from the hypothalamus. The transplanted pituitary tissue retained responsiveness to FSH regulatory peptides. The stimulus for increased FSH secretion after ovariectomy is the removal of negative feedback effector substances from the circulation. We believe that inhibin and, to a lesser degree, oestradiol are likely candidates. ${ }^{8,9}$ Is autonomous FSH secretion a passive process or an active process driven by stimulatory factors produced by pituitary cells? $?^{10}$

Whatever the mechanism might be, our patient serves as an in vivo model of the differential regulation of FSH and $\mathrm{LH}$ secretion.

7. Bishop, W., Fawcett, C.P., Krulich, L. \& McCann, S.M. Acute and chronic effects of hypothalamic lesions on the release of FSH, $\mathrm{LH}$ and prolactin in intact and castrated rats. Endocrinology 1972, 91: 643-656.

8. Rivier, C. \& Vale, W. Inhibin-mediated feedback control follicle-stimulating hormone secretion in female rats. Science 1986, 234: 205-208.

9. Dalkin, A., Haisenlender, D., Ortolano, G., Suhr, A. \& Marshall, J. Gonadal regulation of gonadotropin subunit gene expression: evidence for regulation of follicle-stimulating hormone-beta messenger ribonucleic acid by nonsteroidal hormones in female rats. Endocrinology 1990, 127: 798-924.

10. Knepel, W., Schwaninger, M., Helm, C. \& Kiessel, L. Top concentrations of dimorphin-like immunoreactivity in fractions of rat anterior pituitary cells enriched in gonadotrops. Life Sci 1986, 38: 2363-2367. 